\title{
Childhood evacuation during World War II and subsequent cognitive ability: the Scottish Mental survey 1947
}

\author{
Catherine M Calvin \\ ccalvin@staffmail.ed.ac.uk \\ Jeremy A Crang \\ Lindsay Paterson \\ Ian J Deary \\ University of Edinburgh, UK
}

(Received March 2013 Revised November 2013)

http://dx.doi.org/10.14301/llcs.v5i2.255

\section{Abstract}

Childhood evacuation during World War II was reported by a recent Finnish study to be associated with lower intelligence at follow-up into early and late adulthood (Pesonen et al., 2011, 2013). Opportunities of conducting such natural experiment studies are rare, and yet they contribute to understanding impacts of the early life environment on cognitive development and ability. We investigated the association between evacuation and later cognitive ability in a different national sample. This included 6,082 pre-school boys and girls, 768 of whom were evacuated from their homes in Scotland between 1939 and 1945. The mean duration of evacuation was 14.8 months $(S D=17.8, M d n=7.0)$. Cognitive ability was measured at age 11, in 1947, using the Moray House Test (No. 12). Evacuated children scored on average 1.5 points higher on intelligence test scores relative to their nonevacuated peers (Cohen's $d=0.10, p=.038$ ). The $p$ value was .070 after controlling for potential confounders, including socio-economic status. These findings, in contrast with those from Finland, raise the possibility that evacuation in Scotland may have had a small positive effect on children's cognitive ability scores, due to a difference in educational and environmental exposures. However, analysis of a subset of results using sibling intelligence data, could not rule out selection bias, potentially caused by higher intellectual-ability parents' being more likely to volunteer their children for evacuation. Nevertheless, any supposed adverse effect of evacuation on children in Scotland was not reflected in subsequent intellectual performance

Keywords: cognitive ability, evacuation, intelligence, IQ, Scottish Mental Surveys, socio-economic status, World War II

'The bomber will always get through'

Stanley Baldwin, speech in the House of Commons, 10 November 1932

\section{Introduction}

Cognitive ability, or intelligence, is an important developmental trait, increasing in performance level throughout childhood, and individual differences show quite high stability from adolescence to old age (Deary, Whalley, Lemmon, Crawford, \& Starr, 2000; Gow et al., 2011). The population variance in intelligence, as measured by psychometric cognitive tests, is known to have both genetic and environmental causes (Deary, Johnson, \& Houlihan, 2009). However, in early childhood, when cognitive development is rapidly increasing, the greater of these influences is the environment. This is strongly evidenced by studies of twins in which the genetic influence on a trait can be 
measured alongside shared and unique environmental effects. In early childhood, the shared environment (e.g. that which is common to both members of a twin pair) explains around 50\% to $70 \%$ of variance in intelligence test scores, whereas genetic effects (or heritability) explain around 25\% (Bartels, Rietveld, Van Baal, \& Boomsma, 2002; Davis, Haworth, \& Plomin, 2009). In later childhood, the role of the shared environment diminishes, as heritability becomes more prominent in explaining population intelligence differences (Deary, Johnson, \& Houlihan, 2009; Haworth et al., 2010). It is the early childhood period, therefore, that provides the most fertile period for studying how cognitive ability might be influenced, favourably or unfavourably, by a child's social and physical environment, and the significant events that he or she encounters during that narrow time frame. These dynamic effects may influence behavioural and/or biological systems (including gene expression; see Johnson, 2010) to shape intellectual performance. Identifying the environmental factors that act on developmental processes to affect intelligence is of interest in suggesting early life interventions, or preventative strategies, aimed at optimising cognitive and learning outcomes.

\section{The early environment and cognitive development}

Social deprivation, or socio-economic status, has been identified as a potent environmental factor related to neuro-developmental processes and subsequent intelligence (Hackman \& Farah, 2009; Lawlor et al., 2005). The specific targeting of the learning disadvantages of low income groups has been the subject of an extensive research literature, in which studies have manipulated early life psychosocial exposures, including cognitive stimulation, with the aim of enhancing cognitive development (Hackman, Farah, \& Meaney, 2010; Walker et al., 2011). Evidence from meta-analyses of these early education intervention studies, frequently involving socio-economically-disadvantaged pre-school children, show statistically significant aggregate effect sizes for higher average cognitive ability among children in early life intervention programmes, versus controls (Camilli, Vargas, Ryan, \& Barnett, 2010; Gorey, 2001). Although one of the longest-running intervention studies - the U.S. Government's Head Start programme of educational, health, and social service support interventions - has reported that with longer-term follow-up, the effects on cognition fade with time (Barnett \& Hustedt, 2005), a more time-intensive intervention to promote cognitive stimulation, the Carolina Abecedarian Project, has revealed longerlasting IQ gains. In this randomised prospective trial, 104 pre-school children assigned to a five-year intervention or control group from early infancy were followed up to age 21 years, with assessments of intelligence and academic skills (Campbell, Ramey, Pungello, Sparling, \& Miller-Johnson, 2002). Those who experienced the early life intervention scored an average of 0.5 of a $S D$ higher than controls on the Wechsler Adult Intelligence ScaleRevised at follow-up. However, this strong and lasting intervention effect has not yet been reported elsewhere.

One problem with generalising from the literature on early education interventions is that studies predominantly based on these highly selected groups do not tell us about the full range of possible environmental influences on cognitive development and the effects on individuals across the socio-economic strata. Natural experiment-type studies can provide important observational evidence for potential impacts of early life events on cognitive development and ability across a population. These can be based upon events which some individuals experience, while others do not, and where there are no strong social-selection effects.

\section{Early adverse events and later cognitive abilities}

Opportunities to investigate the impact of early life events on intelligence outcomes within a natural experimental context, and utilising a general population sample, are rare. Yet some research has been conducted into the effects of such events during World War II on subsequent cognitive performance. Records relating to the Dutch famine of 1944-45, caused by a food supply blockage to Western urban areas of the Netherlands, for example, provided the opportunity for a series of studies that tested the outcomes of in utero nutritional deficiency on a regional population group (Roseboom, Painter, van Abeelen, Veenendaal, \& de Rooij, 2011). An early study of this cohort found that mean intelligence test performance in early adulthood was unrelated to the very low calorie intake (400 to 800 per day) of mothers during pregnancy when compared to other 
mothers who had been unaffected by the famine (Stein, Susser, Saenger, \& Morolla, 1975). However, a more recent study with longer follow-up of the cohort, demonstrated detrimental cognitive effects of the famine by older age (De Rooij, Wouters, Yonker, Painter, \& Roseboom, 2010); thus there was a link between poor in utero nutrition and cognitive ageing, but not mean cognitive test performance.

Another wartime event which provided the opportunity for investigating a natural experimenttype intervention on cognitive outcome is childhood evacuation. A recent study reported on 2,725 young Finnish men who served in the country's Defence Forces after the war, and who completed general cognitive ability tests on entry when they were approximately 20 years of age. The authors found that those who had been evacuated during the conflict as children (12\% of the sample and mainly to foster families in Denmark and Sweden) had significantly lower IQ test scores than their peers who had not been evacuated (Pesonen et al., 2011). The difference was equivalent to $0.2 S D$ units, although the effects were more pronounced for those evacuated between the ages of 2 and 4 years, and more so on a test of verbal ability. Within this age group, the difference in the verbal ability subtest score was equivalent to 0.4 of a $S D$. A much longer follow-up study of this Finnish cohort, to age 70, revealed the same effects: a lower performance on the same cognitive tests with a magnitude of one third of a standard deviation (Pesonen et al., 2013). Again, the strongest effect was in verbal reasoning. This latest study provides one of the lengthiest follow-ups of an intervention affecting cognitive ability, far exceeding the time periods so far reported from controlled educational intervention studies, and suggests the potent effects of early life evacuation on cognition throughout a life time.

The Finnish study's findings relate to those from quasi-experimental design studies of early life stressors in childhood and subsequent cognitive ability. For example, adverse childhood preadoption circumstances, as well as post-traumatic stress disorder, have been linked to lower cognitive performance at follow-up, particularly of verbal components, relative to matched controls (Odenstad et al., 2008; Saig, Yasik, Oberfield, Halamandaris, \& Bremner, 2006; Yasik, Saigh, Oberfield, \& Halamandaris, 2007). The study of evacuated children, however, may provide one of the most population-representative of samples, given evacuation affected families across the entire social strata of society (Lloyd, 1979) and across a wide range of cognitive abilities (Boyd, 1944). Furthermore, although the sample is not entirely self-selected if we allow for indirect self-selection via parental choices - and this is taken into account in our analysis - it may nevertheless provide one of the least self-selected samples in this field.

In the present study we largely replicate the methods of the Finnish study, using a similarly-aged cohort of evacuees and non-evacuees, but using a representative sample from Scotland. We examine the association between evacuation and general intelligence as measured in later childhood. As in Finland, the wartime evacuation of Scottish children was organised by the government, but was nonobligatory. It is therefore necessary firstly to describe the Scottish evacuation process in order to understand how the children became evacuees and the potential for heterogeneity between groups when comparing evacuated and non-evacuated children.

\section{Wartime evacuation in Scotland}

During the late 1930s the British government made preparations for the evacuation of the civilian population from areas considered to be the principal industrial and military targets for German bombers in the event of war. Under the official evacuation scheme drawn up for Scotland, the classes of persons for whom evacuation arrangements were made included children of preschool age and their mothers, children of schoolage and their teachers, and expectant mothers. Various districts of Scotland were classified as 'sending areas' (mainly urban areas regarded as being especially vulnerable to attack and with an average population density of 14,000 per square mile) and others as 'receiving areas' (more rural areas considered to be relatively safe and with an average density of 100 per square mile) (Boyd, 1944, pp. 1-5; Stewart \& Welshman, 2006, pp. 104 106).

On the commencement of hostilities in September 1939, the evacuation scheme was put into operation in Scotland. It is estimated that some 175,000 people were evacuated during that month. This figure included 62,000 unaccompanied children, 99,000 mothers and accompanied children, 13,000 teachers and 'helpers', and 1,000 
'other adults' (Titmuss, 1950, p. 562). Furthermore, families were free to make their own private, unofficial arrangements for evacuation - perhaps staying with relatives or friends who lived in safer areas of Scotland - and a considerable number of mothers and children moved out of the target areas having made their own plans (Boyd, 1944). Nevertheless, the number of evacuees was fewer than those anticipated. In Edinburgh, for example, just 32,000 people, equating to one third of the eligible evacuees, departed from the city (Boyd, 1944). Moreover, during the subsequent weeks and months, with little bombing of Scotland during the so-called 'phoney war', many evacuees drifted back to the sending areas. By January 1940 the number of official evacuees across Scotland had fallen to 50,000 (Titmuss, 1950).

In the spring of 1941 the west of Scotland was heavily blitzed. On the clear moonlit nights of 13-14 and 14-15 March the Luftwaffe mounted devastating attacks on Glasgow and Clydeside. Over 1,200 people were killed in these raids and very many houses damaged or destroyed (Crang, 2012). In the wake of the bombing, a further wave of evacuation took place. In September 1941 it was estimated that the number of evacuees across Scotland had risen to 142,000 . They included 27,000 unaccompanied children, 85,000 mothers and accompanied children, 1,000 teachers and 'helpers', and 30,000 'other adults' (Titmuss, 1950, p. 562). Yet, with the attention of the Germans now increasingly on the war against the Soviet Union, and the bombing relenting, many drifted back home once again. By September 1942 there were 55,000 evacuees in Scotland. Thereafter, the number steadily declined so that by March 1945 there were just over 16,000 evacuees (about 11,000 of whom were in fact from English areas but billeted in Scotland) north of the England-Scotland border (Titmuss, 1950).

The dispersal of mothers and children from the large industrial towns and cities of Scotland to the more thinly populated, rural and suburban areas of the country was a massive civic experiment, that incorporated many social and cultural complexities. There were, for example, problems over dialects, with evacuees from Glasgow and the west of Scotland having trouble in being understood in certain regions (Boyd, 1944). There were difficulties in re-locating town dwellers to isolated country districts where they were deprived of their urban social amenities and, as one woman evacuee grumbled, 'there's too much grass about' (Boyd, 1944, p. 71). There were tensions arising from the billeting of Roman Catholics in heavily Protestant areas. And there were antagonisms resulting from the placement of working-class evacuees with middle- or upper-class householders (Boyd, 1944). The cultural divide that existed between some evacuees and their hosts was reflected in complaints from the receiving areas about dirty and verminous city children who seemed to have little concept of modern sanitary habits. One Glasgow mother allegedly told her six-year old child: 'You dirty thing, messing the lady's carpet. Go and do it in the corner' (Titmuss, 1950, p. 122). It is evident, therefore, from the anecdotal evidence that evacuation in Scotland was a wide-scale intervention with the potential to cause disruption and distress to the lives of the children involved.

\section{Aim}

The aim of the present study is to investigate the impact of wartime evacuation on the average cognitive ability of Scottish pre-school children as measured in later childhood. The study uses the 36 Day Sample, a representative subgroup of the Scottish Mental Survey of 1947: a nationwide exercise that tested the intelligence of nearly every 11-year-old child attending school on a single day in 1947. Given previously reported differences in average intelligence test scores between regions of Scotland (Deary, Whalley, \& Starr, 2009; Scottish Council for Research in Education, 1949) - findings that could explain any intelligence difference between evacuees and non-evacuees, if these groups originated from different places - an important aspect of the present study is to consider the association between evacuation and intelligence of children living within the Scottish sending areas only. In a secondary analysis, a sibling comparison study is conducted using a subset of the cohort - the 6-Day Sample - to test whether or not the associated results are biased by confounding (or reverse causation) of familial intelligence, given the selfselected nature of evacuation.

\section{Method}

\section{6-Day Sample}

The Scottish Mental Survey 1947 (SMS1947) was a nationwide exercise, conducted under the auspices of the Scottish Council for Research in Education (SCRE), to investigate the average 
intelligence of Scotland's children (Deary, Whalley 1947 , the survey involved the testing of 70,805 Scots born in 1936, of mean age 11, who completed a general cognitive ability test at their schools. The SMS1947 also collected additional data on subsamples. The '36-Day Sample' is a representative subgroup of the SMS1947 (SCRE, 1953), whose members were selected on the basis of being born on the $1^{\text {st }}, 2^{\text {nd }}$ and $3^{\text {rd }}$ days of each month in 1936. The head teachers of these selected children completed a detailed 25-item Sociological Schedule on their pupils. The total sample with completed Sociological Schedules was $n=6,301$ (3,184 girls and 3,117 boys).

\section{6-Day Sample and siblings}

The 6-Day Sample is an even more select subgroup of the SMS1947 than the 36-Day Sample. It comprised those children born on the first day of the even-numbered months of 1936. Again, this sample was carefully selected in order to achieve social and geographical representativeness of the entire population of 11 year-old schoolchildren living in Scotland in 1947 (MacPherson, 1958). As well as completing the group-administered SMS1947, this cohort completed an individual intelligence test and the same test was given to the members' younger siblings as and when they reached 11 years of age. The 6-Day Sample comprises 1,208 individuals, including 618 girls and 598 boys; intelligence data exist for 1,592 of their siblings.

\section{Research design}

The study is of a natural experiment-type design, assessing differences between an intervention (evacuated) and control (non- evacuated) group on observed variables. The selection of the evacuation group was to a large extent determined by the geographical location of the children's family homes. The government-initiated scheme requested families to organise their children for assembly at local schools, for the evacuation, although attendance was non-obligatory. Figure 1 shows the allocation data of the 36- and 6-Day Samples for evacuated and nonevacuated groups. In the Sociological Schedules of the 36-Day Sample, evacuation status was completed for 6,082 sample members (96.5\% of the cohort) and, among these, 768 (12.6\%) were evacuated during World War II. In the 6-Day Sample, of the cohort of 1,107 with complete evacuation data (91.6\%), 160 children (14.5\%) were evacuated.
\& Starr, 2009; SCRE, 1949). Carried out on $4^{\text {th }}$ June Among these, 91 had one or more sibling with an age 11 intelligence score and, of these, 73 had one or more sibling who was indicated as less likely to have been evacuated.

\section{Sociological Schedule and cognitive ability measures}

Evacuation status was recorded for each child as a 'Yes' or a 'No' in the Sociological Schedule. For those evacuated, even for a few days, head teachers were asked to report the education authority to which the child had been evacuated and the length of evacuation in months. The minimum period of evacuation (e.g. two or three days) was re-coded as 0.1 month.

The schedule incorporated other types of personal data, some of which have associations with intelligence test performance that could be used as control variables in the analysis. Geographical information included the place of residence at birth, which would indicate where the child was evacuated from (with the caveat that a very small proportion might have moved from their locale by the time of evacuation). Family particulars incorporated size of family in 1947; the mother's date of birth which was used to calculate maternal age at birth; and the number of rooms in the home, as well as the number of people living in the home in 1947, which were utilised to estimate an occupancy rate (or overcrowding) variable, i.e. $n$ rooms $/ n$ people. Father's occupation (or that of the main guardian) in 1947 was also recorded. This was re-coded to a fivelevel categorical variable, using the 1951 Classification of Occupations (General Register Office, 1956), with higher values indicating greater socio-economic status (SES): professional (5), intermediate (4), manual or non-manual skilled (3), semi-skilled (2), and unskilled (1). School class size has been included as an education variable in the analysis, given that overcrowded classrooms may have impeded attention and learning (Blatchford, Bassett, \& Brown, 2011; Blatchford, Bassett, Goldstein, \& Martin, 2003). This was calculated from the ratio of number of pupils to full-time teachers in the participating schools. Physical characteristics of the child were further recorded, including height (in inches) and weight (in pounds). If the child had any physical disability these were reported too. These included defective vision, deafness, epilepsy, meningitis, chorea, encephalitis, and congenital paralysis. 
General intelligence was measured using the Moray House Test (No. 12), which was groupadministered within schools by teachers across the whole of Scotland in the SMS1947. This began with an eight-item practice test, followed by the actual test which incorporated 71 items. These assessed a range of verbal and non-verbal reasoning skills and used a combination of different types of questions. For example, verbal items included same-opposites, word classification, analogies, proverbs, mixed sentences, and reasoning. Non-verbal aspects featured arithmetic, spatial items, and cypher decoding (see Deary, Whalley, \& Starr, 2009, for the full list). Teachers read out verbal instructions and children then completed as many items as possible within a 45 -minute session. The maximum possible score for the test was 76. Cases were excluded from the analysis if scores were recorded zero $(n=$ 53).

The individually-administered intelligence test given to the 6-Day Sample, and their younger siblings, was the Terman-Merill version (Form L) of the Stanford Binet test (Terman \& Merrill, 1937). The testers were trained volunteers, largely comprising educational psychologists (Maxwell, 1961). The Terman-Merill test included 129 questions relating to verbal and non-verbal reasoning. Individual performance scores were converted to standardised scores, where $M=100$ and $S D=15$. These data are used to assess possible selection bias in our main results (see the statistical analysis section for further details).

Figure 1. Sample selection and assignation to evacuated and non-evacuated groups

\section{Enrolment}
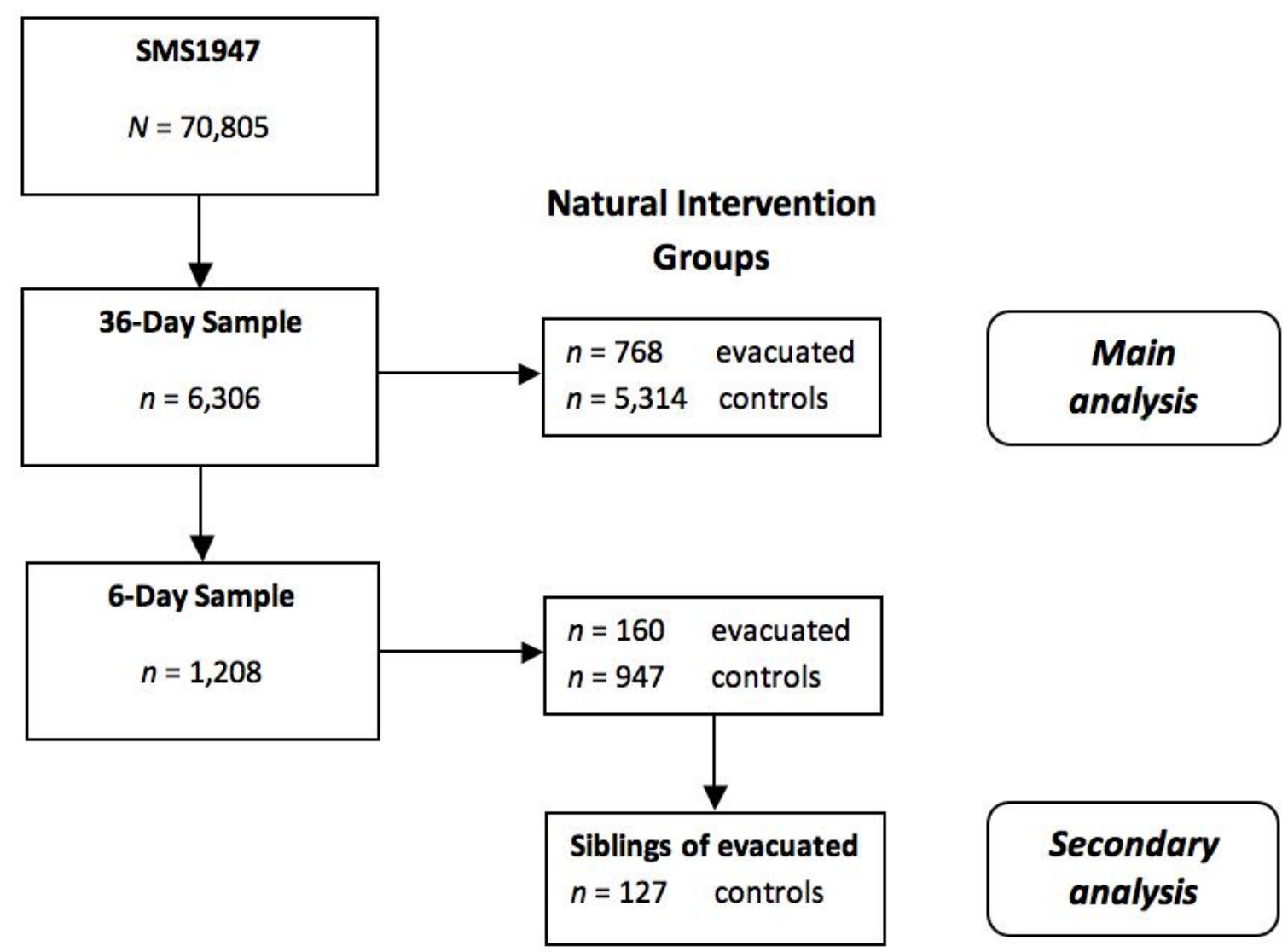

Note. Secondary analysis, to account for confounding by familial intelligence, included evacuated 6-Day Sample members $(n=160)$ and their siblings who were not evacuated $(n=127)$. 


\section{Statistical analysis}

Independent samples t-tests and chi-square tests were used to investigate group differences between evacuated and non-evacuated children on continuous and categorical variables respectively. These were conducted for the entire sample and then repeated for only those children born within evacuation sending areas given the sociodemographic differences between sending and nonsending areas. Linear regression was carried out to test whether evacuation status predicted intelligence test scores independently of potentially confounding factors. Covariates included in the model were those measures from the Sociological Schedule that significantly correlated with the Moray House test score $(p<.05)$. Models were tested for multi-collinearity. These analyses were conducted in IBM SPSS Statistics Version 19.

The above analyses looked upon cognition as the outcome and evacuation as a possible cause. However, for genetic and environmental reasons, the intelligence of children and their parents is correlated. It is possible that the decision to evacuate could have tapped into parents' intelligence and that any evacuation-intelligence link might in part be reverse causation/confounding. So, to test this likelihood, we used data from the 6-Day Sample and their siblings. Those younger siblings born after the main evacuation years (1939 to 1941) were less likely to have been evacuated during World War II, compared to those born before or during this period. A comparison of the mean intelligence test score of evacuated 6-Day Sample members with that of their siblings, who were unlikely to have been evacuated, would formally test whether confounding by parental intelligence influenced an evacuation-intelligence association. If no difference was to exist between the mean IQ performance score of evacuees, relative to their non-evacuee younger siblings, then parental selection bias, or other selection bias operating at the level of the family, remained plausible.

To test whether there was a difference in the mean IQ of evacuated and non-evacuated siblings, multilevel modelling was applied in MLwiN 2.26 to take account of clustering of siblings within families, thus implicitly allowing for genetic and environmental correlations within families.

The model to be fit was:

$$
\mathrm{IQ}=a+b \cdot S+u+e
$$

where $a$ and $b$ are regression coefficients to be estimated, and $S$ is a dichotomous indicator of not having been (' 1 ') or having been (' $O$ ') evacuated: that is, ' 1 ' means a sibling and ' 0 ' a 6 -day sample member. Thus $b$ is the coefficient of interest. The term $u$ varies randomly at the family level: Normal, mean 0 , variance $\operatorname{Var}(u)$. The term $e$ varies randomly at the individual level: Normal, mean 0 , variance $\operatorname{Var}(e)$. The terms $\mathrm{u}$ and $\mathrm{e}$ are uncorrelated.

$\operatorname{Var}(u)$ and $\operatorname{Var}(e)$ are to be estimated. The within-family correlation is:

$$
\operatorname{Var}(\mathrm{u}) /[\operatorname{Var}(\mathrm{u})+\operatorname{Var}(\mathrm{e})]
$$

\section{Results}

\section{Description and comparison of evacuated and non-evacuated groups}

Table 1 shows the differences between all evacuated and all non-evacuated children according to the Sociological Schedule variables and Moray House Test scores. The ratio of girls to boys was slightly higher among evacuated children (52.8 vs $47.2 \%$ ) relative to non-evacuated children (50.1 vs $49.9 \%)$, but this difference was not statistically significant $(\chi 2=2.10, d f=1, p=.147)$. The evacuated children scored on average 1.3 points higher (SE difference $=0.6$ ) on the Moray House test compared to their non-evacuated peers, which was statistically significant $(t=-2.15, d f=929.3, p=$ .03) albeit a low effect size (Cohen's $d=.08$ ). This apparent boost in performance was recorded despite the fact that in 1947, at age 11, the evacuated children were of significantly lower average socio-economic status according to their father's occupational code $(\chi 2=29.6, d f=4, p<$ $.001)$ and had a higher room occupancy rate in the home $(t=-4.47, d f=985.5, p<.001)$; they were in larger school classes $(t=-12.7, d f=1097.1, p<$ .001); they were lighter in weight, by one pound on average, relative to non-evacuated children ( $t=$ 2.57, $d f=6002, p=.01)$; and they showed a greater incidence of physical disability $(\chi 2=16.5, d f=1, p<$ .001). The evacuated children were born in specific Scottish localities and it is possible that regional trends may have produced some of the sociological differences, and indeed the intelligence difference, between the two groups. For example, more than half of evacuated children were born in Glasgow $(58 \%)$ and the rest were mainly born in Edinburgh (14\%), Dundee (7\%), Clydebank (5\%), and Greenock 
(3\%). In contrast, non-evacuees were more evenly distributed across a range of urban and rural areas of Scotland, with only $20 \%$ and $7 \%$ born in the major cities of Glasgow and Edinburgh respectively. Table 2 reports differences between evacuated and non-evacuated children born in Scotland's evacuation sending areas only. A noticeable difference from Table 1 is that within sending areas there were no longer socio-economic differences between the two groups. Yet the higher mean intelligence score of evacuated children persisted: a 1.5-point mean $(S E=0.7)$ advantage relative to nonevacuees $(t=-2.08, d f=1186.9, p=.038)$. Furthermore, evacuees still ended up in larger classes after the war $(t=-4.41, d f=1302.8, p<$ $.001)$ and showed a significantly greater incidence of physical disability compared to their nonevacuated peers $(\chi 2=7.33(1), p=.007)$.

Table 1. Comparison of evacuated and non-evacuated children in the 36-Day Sample

\begin{tabular}{|c|c|c|c|c|c|}
\hline & \multicolumn{2}{|c|}{ Evacuated } & \multicolumn{2}{|c|}{ Not evacuated } & \multirow{2}{*}{$\begin{array}{c}M \text { (and SE) difference; } \\
\text { significance value }\end{array}$} \\
\hline & $n(\%)$ & $M(S D)$ & $n(\%)$ & $M(S D)$ & \\
\hline Intelligence score & 688 & $37.5(14.5)$ & 4,810 & $36.2(15.5)$ & $\begin{array}{r}-1.27(0.60) ; \quad p= \\
.032\end{array}$ \\
\hline Maternal age at birth & 751 & $28.4(5.9)$ & 5,107 & $28.8(6.1)$ & $0.35(0.24) ; \quad p=.142$ \\
\hline Height (inches) & 763 & $53.8(2.9)$ & 5,258 & $54.0(2.9)$ & $0.14(0.11) ; \quad p=.198$ \\
\hline Weight (pounds) & 763 & $68.6(10.3)$ & 5,241 & $69.7(10.9)$ & $1.08(0.42) ; \quad p=.010$ \\
\hline Family size & 768 & $3.71(2.00)$ & 5,279 & $3.89(2.31)$ & $0.17(0.08) ; \quad p=.028$ \\
\hline Occupancy rate & 769 & $2.30(1.18)$ & 5,266 & $2.10(1.13)$ & $-0.20(0.04) ; \quad p<001$ \\
\hline School class size & 772 & $33.8(5.7)$ & 5,300 & $31.0(6.6)$ & $-2.85(0.22) ; \quad p<001$ \\
\hline $\begin{array}{l}\text { Fathers' occupation } \\
\text { professional }\end{array}$ & $10(1.3)$ & & $52(1.0)$ & & $\begin{array}{r}\chi 2(d f) \\
\text { significance value }\end{array}$ \\
\hline intermediate & $43 \quad(5.6)$ & & 459 (8.8) & & \\
\hline skilled & $420(54.8)$ & & $2,613(50.1)$ & & \\
\hline semi-skilled & $114(14.9)$ & & $1,091(20.9)$ & & \\
\hline unskilled & $179(23.4)$ & & $1,002(19.2)$ & & $\chi 2=29.6(4), p<.001$ \\
\hline Female & $408(52.8)$ & & $2,660(50.1)$ & & $\chi 2=2.10(1), p=.147$ \\
\hline Physical disability & $94(12.2)$ & & 417 (7.9) & & $\chi 2=16.5(1), p<.001$ \\
\hline
\end{tabular}

Notes. Intelligence data were missing for 588 individuals (9.6\%) of the sample for whom evacuation status was recorded. There was no significant difference in the rate of evacuation among those with IQ data (14.3\%) and those without (16.7\%): Pearson chi-squared $=1.506(1), p=.220$. 
Table 2. Comparison of evacuated and non-evacuated children born within sending areas of evacuation

\begin{tabular}{|c|c|c|c|c|c|}
\hline & \multicolumn{2}{|c|}{ Evacuated } & \multicolumn{2}{|c|}{ Not evacuated } & \multirow{2}{*}{$\begin{array}{c}M \text { (and } S E \text { ) difference; } \\
\text { significance value }\end{array}$} \\
\hline & $n(\%)$ & $M(S D)$ & $n(\%)$ & $M(S D)$ & \\
\hline Intelligence score & 603 & $37.5(14.5)$ & 1,571 & $36.0(15.9)$ & $-1.48(0.71) ; \quad p=.038$ \\
\hline Maternal age at birth & 658 & $28.5(6.0)$ & 1,658 & $28.9(6.3)$ & $0.41(0.28) ; \quad p=.152$ \\
\hline Height (inches) & 668 & $53.7(2.9)$ & 1,719 & $53.7(2.9)$ & $-0.08(0.13) ; \quad p=.553$ \\
\hline Weight (pounds) & 668 & $68.3(10.1)$ & 1,720 & $68.0(10.2)$ & $-0.29(0.46) ; \quad p=.535$ \\
\hline Family size & 673 & $3.78(2.00)$ & 1,728 & $3.80(2.19)$ & $0.01(0.09) ; \quad p=.885$ \\
\hline Occupancy rate & 673 & $2.36(1.19)$ & 1,723 & $2.36(1.29)$ & $-0.02(0.06) ; \quad p=.685$ \\
\hline School class size & 675 & $34.0(5.4)$ & 1,737 & $33.0(5.7)$ & $-1.11(0.25) ; \quad p<.001$ \\
\hline Fathers' occupation & & & & & $\chi 2(d f)$ \\
\hline professional & $7(1.0)$ & & $16(0.9)$ & & significance value \\
\hline intermediate & $32(4.8)$ & & $109(6.4)$ & & \\
\hline skilled & $363(54.2)$ & & $888(52.1)$ & & \\
\hline semi-skilled & $107(16.0)$ & & $261(15.3)$ & & \\
\hline unskilled & $161(24.0)$ & & $430(25.2)$ & & $\chi 2=2.99(4), p=.560$ \\
\hline Female & $355(52.6)$ & & $863(49.6)$ & & $\chi 2=1.71(1), p=.191$ \\
\hline Physical disability & $84(12.5)$ & & $153(8.8)$ & & $\chi 2=7.33(1), p=.007$ \\
\hline
\end{tabular}

\section{Duration and destination of evacuation}

The duration of evacuation was recorded for 731 evacuees, leaving only $4.8 \%$ of the sample with missing data. Figure 2 shows the positive skew of evacuation duration for the sample, as well as its wide distribution ( $M=14.8$ months, $S D=17.8)$. It is clear that some children were evacuated for a short period of a few days or weeks, whereas others spent the entire duration of the war in the receiving homes. The average duration of evacuation did not differ significantly for boys and girls (Mann Whitney U Test: $p=.340$ ). Moreover, duration of evacuation as a continuous variable was not associated with intelligence test score $\left(r_{s}=.054, p=.165\right)$. In categorising the evacuated sample into five groups, ranging from $<1$ month to $>1$ year, the average intelligence test scores increased incrementally with longer duration of evacuation (see Table 3). However, this was not close to reaching a level of statistical significance in an ANOVA test $(F=.493, d f$ $=4, p=.741$ ).

Among the 741 evacuees on whom there were data on the education authority of their evacuation destination, $96.6 \%$ were accommodated within Scotland, while the remainder went (presumably privately) to England, Wales or Ireland. The Scottish council region to receive the most evacuated children was Argyll and Bute, taking in over $10 \%$ of the sample. Other popular regions were Aberdeenshire, Perth and Kinross, South Lanarkshire, and Dumfries and Galloway, each receiving $6 \%$ to $7 \%$ of the sample. Given the geographical dispersion of evacuees in this sample within these receiving areas, as well as the lack of data on the receiving homes and the host families, this aspect of evacuation can only be reported on, and is of limited value in statistical analysis. 
Figure 2. Distribution of evacuation duration in the 36-Day Sample

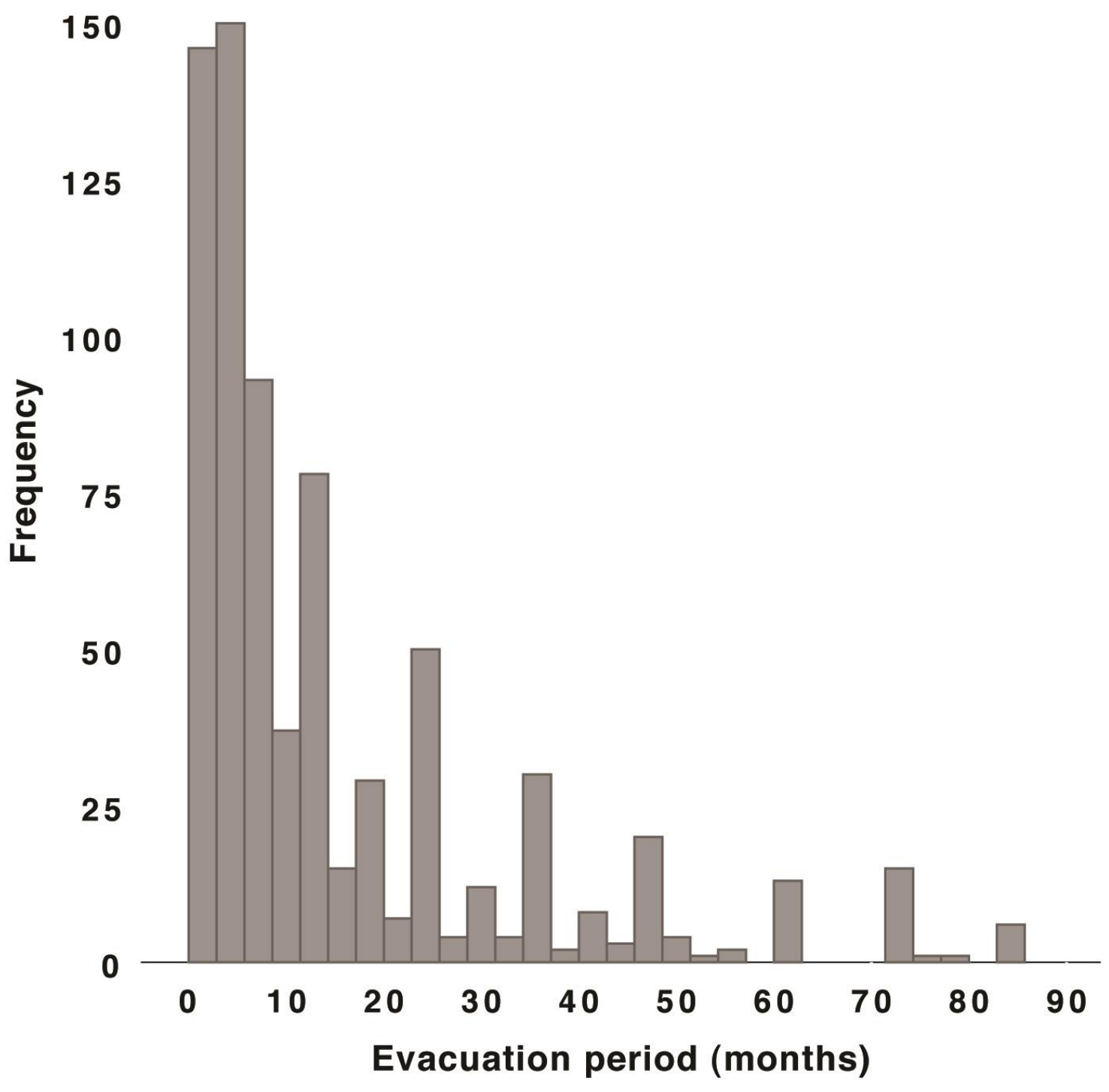

Notes. $n=731 ; M d n=7.0$ months

Table 3. Mean intelligence test scores by evacuation duration group

\begin{tabular}{lccc} 
& $\boldsymbol{n}$ & $\boldsymbol{M}$ & $\boldsymbol{S D}$ \\
\hline Not evacuated & 1,571 & 36.04 & 15.86 \\
< 1 month & 33 & 35.45 & 14.61 \\
One to 3 months & 94 & 36.85 & 15.16 \\
3 to 6 months & 123 & 37.24 & 15.11 \\
6 to 12 months & 104 & 38.11 & 14.69 \\
$>1$ year & 249 & 37.94 & 13.89
\end{tabular}




\section{Regression analysis}

Regression analyses were carried out using data only from those children born within the World War II sending areas, and who had completed data on all variables $(n=2,091)$. The positive association between evacuation and intelligence, when evacuation status was the only independent variable in the regression model, reached a trend level of statistical significance in this slightly reduced sample ( $B=.088, \mathrm{Cl} 95 \%-.006$ to $.183, p=$ .067). In models adjusting for single additional covariates in turn, no variable was found to attenuate the magnitude of this trend effect (results not shown), suggesting a lack of potential confounding or mediation by our observed covariates. There was no evidence either that socio- economic status moderated the association between evacuation and intelligence; that is, the relatively higher mean IQ performance score for evacuees was apparent across socio-economic groups (see Figure 3). By adjusting for physical disability, however, the effect of evacuation on intelligence test score increased slightly and became statistically significant $(B=.097, \mathrm{Cl} 95 \%$ .003 to .192, $p=.044)$. Therefore, without accounting for the higher frequency of physical disability among evacuees, the association between evacuation and intelligence would have been less evident. Nevertheless, it was still detectable and not wholly suppressed by the difference in frequency of physical disability.

Figure 3. Mean intelligence by socio-economic status and evacuation group

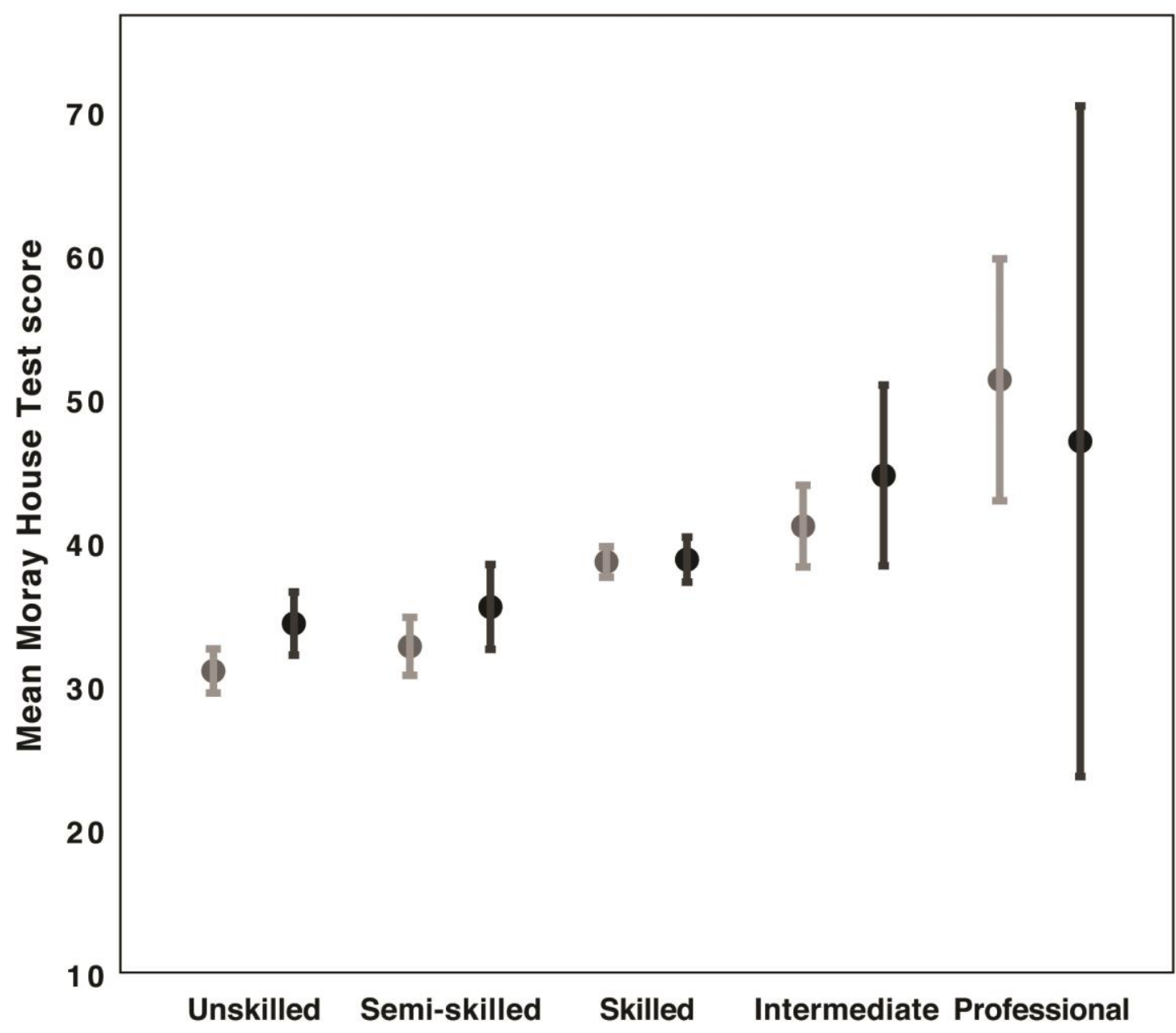

Notes. Moray House intelligence test mean performance score (maximum 76) according to socio-economic status and evacuation status groups. Black and grey error bars represent evacuated and non-evacuated groups respectively. Evacuees perform above non-evacuees across the social strata, with the exception of the professional groups that have very low sample sizes. 
Table 4 shows the beta coefficients and their $95 \%$ confidence intervals, in multivariate regression, of evacuation status and covariates in predicting a one $S D$ increase in Moray House test score. The model accounted for $18.4 \%$ of the variance in the dependent variable. The results show that, after controlling for highly significant predictors of intelligence, including socio-economic status indicators, physical disability, and family size, the association between evacuation status and higher intelligence test score was a non-significant trend $(B$ $=0.80,95 \% \mathrm{Cl}-.006$ to $-.166, p=.070)$.

\begin{tabular}{|c|c|c|c|c|}
\hline & $B$ & $\mathrm{Cl} 95 \%$ & Partial $r$ & sig. \\
\hline Female & .090 & $.013, .168$ & .050 & .022 \\
\hline Fathers' SES & .124 & $.082, .167$ & .124 & $<.001$ \\
\hline Occupancy rate & -.103 & $-.139,-.068$ & -.125 & $<.001$ \\
\hline Evacuated & .082 & $-.004, .168$ & .041 & .062 \\
\hline Disability & -.156 & $-.285,-.027$ & -.052 & .018 \\
\hline Height & .073 & $.054, .091$ & .164 & $<.001$ \\
\hline Weight & .002 & $-.003, .007$ & .018 & .419 \\
\hline School class size & -.003 & $-.010, .004$ & -.017 & .441 \\
\hline Family size & -.075 & $-.095,-.055$ & -.161 & $<.001$ \\
\hline
\end{tabular}

Notes. Analysis restricted to sample members born in sending areas $(n=2091)$. Model excluded maternal age, which was not associated with intelligence in the sample $(p>.05)$.

A weighted variable was included in the model to account for potential bias from missing intelligence data. This was calculated from logistic regression with data on the full cohort, and used the inverse probability of each case having valid intelligence data, as predicted by evacuation status, physical disability status, height, weight, class size, and family size. This made negligible difference to the coefficients as compared to a model without it.

\section{Sibling analysis}

In the subgroup comparison between 6-Day Sample members and their siblings, the nonevacuation status of siblings $(n=127)$, relative to the evacuation status of 6-Day Sample members $(n$ $=160$ ), was significantly associated with lower mean scores on the Terman-Merrill intelligence test $(B=-5.013, S E=2.177, p=.02)$. However, it was important to redo the analysis allowing for the clustering of data points within families. This is because it is known that, within the 6-Day Sample, larger families had lower mean IQ scores (see Deary, Whalley, \& Starr, 2009, p. 22). In this comparison, therefore, whereas any sibling from a 6-Day Sample evacuated member in a two-child family adds one IQ score to the control group, those with more siblings add a greater number, and these will tend to be lower, thus spuriously reducing the mean of the sibling control group. In other words, this analysis is sub-optimal because the control group is more biased towards the mean IQ of larger families than the 6-Day Sample evacuated group. The within-family correlation on intelligence score was $r=0.53$. The beta coefficient in the multilevel model for the difference was -2.024 (SE = 1.794). Although the non-evacuated status of siblings, relative to the evacuated status of 6-Day Sample members, was still associated with lower mean IQ scores, this effect was no longer statistically significant once family clustering of intelligence test scores was accounted for $(p=0.26)$. 


\section{Discussion}

An analysis of a representative sample of Scottish schoolchildren, including boys and girls, in the 1940s reveals that, in contrast to a previous study of a Finnish male cohort, those evacuated during World War II scored on average 1.3 points above non-evacuated children (or $10 \%$ of a SD) on the Moray House Test: a small but statistically significant difference. This effect was evident despite the fact that the wartime evacuees were from more disadvantaged backgrounds, suffered from a greater proportion of disabilities, and were being educated in schools with larger class sizes after World War II, and might thus be expected to have had lower, rather than higher, IQ levels than their contemporaries. What is also relevant is that, given that the bulk of Scottish evacuations took place in 1939-1941, it is likely that most of the evacuated children in the 36-Day sample would have been between the ages of 3 and 5 years when they were billeted in receiving areas. This is the age band of the Finnish evacuees who later performed particularly poorly in their IQ tests (Pesonen et al., 2011).

In seeking to explain these Scottish results, it should be acknowledged that there are variables on which the 36-Day sample does not provide information. We do not know, for example, which children were evacuated under the official government scheme or under private arrangements; whether or not they were accompanied by their mothers or other siblings; in what types of households in the receiving areas they were accommodated; whether they drifted back home and then returned to a receiving area in the wake of the heavy bombing; and the precise ages at which they were evacuated.

With these provisos, the association between evacuation status and age- 11 IQ test performance was unlikely to be explained by differences in the sending areas versus non-sending areas: a comparison of the test results of evacuees and nonevacuees born within the same sending areas found a 1.5-point mean advantage in IQ to evacuees. Nor can the differences be explained by length of evacuation, given that duration was unrelated to intelligence test score, whether measured as a continuous or categorical variable.

We are thus left to consider other explanations. Results from our sibling analysis suggest we cannot rule out the possibility of self-selection bias, because although evacuated children scored above the average of their non-evacuated siblings, this was not a statistically significant difference. Parental intelligence may have confounded the association between evacuation and IQ we observed, just as maternal intelligence has previously been shown to confound the associations between childhood intelligence and birth weight (Deary, Der, \& Shenkin, 2005), breastfeeding (Der, Batty, \& Deary, 2006), and smoking (Batty, Der, \& Deary, 2006). Such an explanation of self-selection is consistent with the absence of any differential effect of differing lengths of time of having been evacuated. Given the self-selecting nature of the evacuation scheme, the judgements that had to made by parents about the nature of risk and the efficiency of government arrangements, as well as the practical steps they had to take to arrange evacuation (whether under the official scheme or privately), it is conceivable that the better performance of evacuated children might be in some measure due to the fact that they were the children of parents with higher IQs, and the results could therefore relate in part to heritable intelligence. There is also a chance that parents did not randomly select their siblings for evacuation and might have selected only those children who they believed had the greatest ability to cope with a new home environment. Of course, there are other plausible confounders - including differences in social and/or economic resources between evacuated and non-evacuated children, which also happen to be correlates of IQ - but such differences were not observed in the main analysis of children within sending areas, at least according to parental socio-economic status and home overcrowding. Another interpretation of our sibling results is highlighted by the authors of a previous sibling comparison study who suggested that "spillover effects" from children receiving specialist educational intervention onto their siblings not receiving the intervention may occur and produce conservative treatment effects on intelligence (Currie \& Thomas, 1993). Therefore, it is possible that within our sample any positive effects of evacuation on children's cognitive abilities were transmitted, in turn, to their younger siblings who were not evacuated, perhaps via general knowledge, approaches to learning, and/or engagement with the environment. 
Whereas self-selection at evacuation might be a likely explanation for the evacuees having higher mean intelligence, one must consider the alternative: that experiences specific to the evacuees, or indeed non-evacuees, could have caused this group difference. To deal with the experience of the 11 year-old non-evacuees first, it is conceivable that the lower test results among some of them - especially those who remained in Scottish cities - were associated with dislocations to their family lives as a result of long hours of parental war work, disruptions to schooling in the sending areas (Rutter, 1985), and the traumatic impact of bombing on subsequent learning (Stermac, Clarke, \& Brown, 2013). In March 1940, for example, $96 \%$ of all primary schools in receiving areas were open full-time, whereas in the sending areas, $5 \%$ only were running full-time (Lloyd, 1979). Furthermore, how successful the attempt was to minimise educational disruption in sending areas varied between cities. Dundee suffered comparatively longer school closures than other cities, whereas Edinburgh, a model city for the whole of Britain, demonstrated "speedy restoration of her educational service" (Lloyd, 1979, pp. 69). The discrepancy between mean intelligence test scores of evacuated and non-evacuated children in the present sample did appear to be greater in those children from Dundee (3.45 points), relative to Glasgow (1.94 points) and Edinburgh (0.95 points) (data not presented), which could support this hypothesis. However, given that most school disruption came at the beginning of the war in Scotland (Lloyd, 1979), it is not clear how the 36Day Sample non-evacuees from these cities would have been affected by insufficient schooling, given that most were of pre-school age at the time.

Conversely, we must also consider the possibility that the test results were partly the result of the positive impact of evacuation (even if experienced only for short periods) on the children concerned. Although the absence of cumulative environmental effects of being placed in a billeted home were shown in the data, 'early life stresses' of evacuation might have had a beneficial impact on average cognitive ability since they acted as a stimulant to mental development through a shift in physical and/or social environments. In this regard, a period spent in an unfamiliar billet in a Scottish receiving area, at a formative age, might have encouraged greater communication skills and problem-solving behaviour. It may also be the case that the children, and the parents who accompanied them, were introduced to a wider range of stimuli, to the 'ways' of the educated middle classes, and potentially greater social and economic resources. For example, a shift to the dietary patterns of more affluent/rural host families may have brought with it nutritional benefits which enhanced early infant cognitive development. That such factors might have outweighed any potential adverse effects of evacuation may only have been possible given that many Scottish pre-school children, while separated from their fathers, were evacuated with their mother and/or siblings (Boyd, 1944). This would surely have buffered the trauma of leaving home. In contrast, in the previous Finnish study, the evacuation experience may have been a greater 'stressor', given that children were routinely separated from both parents and billeted in a foreign country where a different language might have been spoken by the hosts (Pesonen et al., 2011). Compared to that experience, the relevant linguistic variation within Scotland was less, being that of dialects rather than (for example) the difference between Finnish and Swedish noted by Pesonen et al. (2011: 337): the official evacuation scheme operated outside the areas where Gaelic was the dominant language. Furthermore, the mean length of evacuation was slightly longer for the Finnish (1.7 years) compared to Scottish (1.3 years) children. The hypothesis that Scottish evacuation stimulated cognitive development is reminiscent of the intensive pre-school intervention programmes to boost intellectual outcomes, particularly among socio-economically disadvantaged children (Campbell et al., 2002; Currie \& Thomas, 1993). Hunt (2010) suggests that the micro-environment of the home has 'a substantial influence on intelligence during the early childhood years' and it is possible that the wartime evacuation of thousands of Scottish children to temporary new homes increased their average IQ performance. To support this, a very small study by Boyd (1941) in the immediate aftermath of the first Scottish evacuees returning home, in which ten 10-14 yearold children who were evacuated were compared to 46 of their peers not evacuated, found that among evacuees, improvements were shown in speech, obedience and general good behaviour, and there was less quarrelling and grumbling, whereas among those not evacuated, these behaviours 
appeared to have deteriorated. Although this was not the age group under investigation in the present study, it does suggest positive outcomes for some older children evacuated during World War II in Scotland and perhaps was the result of examples of better behaviour and conduct, set in the receiving homes.

If we accept the notion of the positive impact of evacuation on cognitive performance, in wider historical terms the fact that 11 year-old former Scottish child evacuees performed better in their IQ tests than non-evacuees may give some credence to the so-called levelling effects of the Second World War on British society (Marwick, 1970). It has been argued that pre-war Scottish educational policy and practice, though widening opportunity significantly compared to earlier times, still tended to favour the children of middle-class homes, and that the war accentuated this divide (Lloyd, 1992, p. 334). However, given that evacuees included individuals from urban working-class backgrounds, and from some of the most deprived areas of Scotland, the experience of war might appear to have benefited these children cognitively. Indeed, while the poor condition of many of the evacuees arriving in the reception areas, is claimed to have helped inspire a wartime reformist consensus in Britain that paved the way for improved welfare provision (Titmuss, 1950), perhaps evacuation also helped in a small manner to boost the life chances of Scotland's disadvantaged children in more cerebral ways.

Without data on baseline cognitive ability of evacuees and non-evacuees in this natural experimental-design study, we can only speculate as to the extent to which evacuation (or nonevacuation) affected cognitive performance, if at all, or whether the groups differed before intervention. One relevant observation was the greater frequency of individuals with childhood physical disability in the higher cognitive performance group (evacuees), when one would have expected their presence to reduce mean cognitive performance relative to non-evacuees, all other factors being equal. Indeed without adjusting for physical disability there was no statistically significant difference in mean group intelligence. Nevertheless, although there are certain understandable attractions to the positive impact case, given that our sibling-analysis results could not confidently rule out self-selection effects, perhaps the likelihood that evacuees and nonevacuees started out with different mean cognitive abilities should remain as our most cautious explanation for this study's findings.

\section{Acknowledgements}

The work was supported by a UK cross-council Lifelong Health and Wellbeing initiative grant (MRCG1001401), which includes a research fellowship for CMC. IJD and CMC are members of The University of Edinburgh Centre for Cognitive Ageing and Cognitive Epidemiology, part of the cross council Lifelong Health and Wellbeing initiative (G0700704/84698). Funding from the Biotechnology and Biological Sciences Research Council (BBSRC), Economic and Social Research Council (ESRC), Engineering and Physical Sciences Research Council (EPSRC), and Medical Research Council (MRC), is gratefully acknowledged.

\section{References}

Barnett, W.S., \& Hustedt, J.T. (2005). Head Start's lasting benefits. Infants \& Young Children, 18, 16-24. http://dx.doi.org/10.1097/00001163-200501000-00003

Bartels, M., Rietveld, M.J.H., Van Baal, G.C.M., \& Boomsma, D.I. (2002). Genetic and environmental influences on the development of intelligence. Behavior Genetics, 32, 237-249. http://dx.doi.org/10.1023/A:1019772628912

Batty, G.D., Der, G., \& Deary, I.J. (2006). Effect of maternal smoking during pregnancy on offspring's cognitive ability: empirical evidence for complete confounding in the US National Longitudinal Survey of Youth. Pediatrics, 118, 943-950. http://dx.doi.org/10.1542/peds.2006-0168

Blatchford, P., Bassett, P., \& Brown, P. (2011). Examining the effect of class size on classroom engagement and teacher-pupil interaction: Differences in relation to pupil prior attainment and primary vs. secondary schools. Learning and Instruction, 21, 715-730. http://dx.doi.org/10.1016/j.learninstruc.2011.04.001

Blatchford, P., Bassett, P., Goldstein, H., \& Martin, C. (2003). Are class size differences related to pupils' educational progress and classroom processes? Findings from the Institute of Education Class Size 
Study of children aged 5-7 years. British Educational Research Journal, 29, 709-730. http://dx.doi.org/10.1080/0141192032000133668

Boyd, W. (1941). The effects of evacuation on the children. British Journal of Educational Psychology, 11, 120-126. http://dx.doi.org/10.1111/i.2044-8279.1941.tb02153.x

Boyd, W. (1944). Evacuation in Scotland: A record of events and experiments. London: University of London Press Ltd.

Camilli, G., Vargas, S., Ryan, S., \& Barnett, S. (2010). Meta-analysis of the effects of early education interventions on cognitive and social development. Teachers College Record, 112, 579-620.

Campbell, F.A., Ramey, C.T., Pungello, E., Sparling, J., \& Miller-Johnson, S. (2002). Early childhood education: Young adult outcomes from the Abecedarian Project. Applied Developmental Science, 6, 42-57. http://dx.doi.org/10.1207/S1532480XADS0601 05

Crang, J.A. (2012). The Second Word War. In E.M. Spiers, J.A. Crang \& M.S. Strickland (Eds.) A military history of Scotland. Edinburgh: Edinburgh University Press.

Currie, J., \& Thomas, D. (1993). Does Head Start make a difference? NBEW Working Paper No. 4406, Issued in July 1993. US: The National Bureau of Economic Research. Accessed 24th May 2013 from: http://www.nber.org/papers/w4406

Davis, O.S.P., Haworth, C.M.A., \& Plomin, R. (2009). Dramatic increase in heritability of cognitive development from early to middle childhood: An 8-year longitudinal study of 8,700 pairs of twins. Psychological Medicine, 20, 1301-1308.

De Rooij, S.R., Wouters, H, Yonker, J.E., Painter, R.C., Roseboom, T.J. (2010). Prenatal under-nutrition and cognitive function in late adulthood. Proceedings of the National Academy of Sciences of the United States of America, 107, 16881-16886. http://dx.doi.org/10.1073/pnas.1009459107

Deary, I.J., Der, G., \& Shenkin, S.D. (2005). Does mother's IQ explain the association between birth weight and cognitive ability in childhood. Intelligence, 33, 445-454. http://dx.doi.org/10.1016/j.intell.2005.05.004

Deary, I.J., Johnson, W., \& Houlihan, L.M. (2009). Genetic foundations of human intelligence. Human Genetics, 126, 215-232. http://dx.doi.org/10.1007/s00439-009-0655-4

Deary, I.J., Whalley, L.J., Lemmon, H., Crawford, J.R., \& Starr, J.M. (2000). The stability of individual differences in mental ability from childhood to old age: Follow-up of the 1932 Scottish Mental Survey. Intelligence, 28, 49-55. http://dx.doi.org/10.1016/S0160-2896(99)00031-8

Deary, I.J., Whalley, L.J., \& Starr, J.M. (2009). A lifetime of intelligence: Follow-up studies of the Scottish Mental Surveys of 1932 and 1947. American Psychological Association: Washington DC, U.S. http://dx.doi.org/10.1037/11857-000

Der, G., Batty, G.D., \& Deary, I.J. (2006). Effect of breast feeding on intelligence in children: Prospective study, sibling pairs analysis, and meta-analysis. British Medical Journal 333, 945. http://dx.doi.org/10.1136/bmj.38978.699583.55

General Register Office. (1956). Census 1951, Classification of Occupations. H.M. Stationary Office.

Gorey, K.M. (2001). Early childhood education: A meta-analytic affirmation of the short- and long-term benefits of educational opportunity. School Psychology Quarterly, 16, 9-30. http://dx.doi.org/10.1521/scpq.16.1.9.19163

Gow, A.J., Johnson, W., Pattie, A., Brett, C.E., Roberts, B., Starr. J.M., \& Deary, I.J. (2011). Stability and change in intelligence from age 11 to ages 70,79, and 87: the Lothian Birth Cohorts of 1921 and 1936. Psychology and Aging, 26, 232-240. http://dx.doi.org/10.1037/a0021072

Hackman, D.A., \& Farah, M.J. (2009). Socioeconomic status and the developing brain. Trends in Cognitive Sciences, 13, 65-73. http://dx.doi.org/10.1016/j.tics.2008.11.003

Hackman, D.A., Farah, M.J., \& Meaney, M.J. (2010). Socioeconomic status and the brain: Mechanistic insights from human and animal research. Nature Reviews Neuroscience, 11, 651-659. http://dx.doi.org/10.1038/nrn2897

Haworth, C.M.A., Wright, M.J., Luciano, M., Martin, N.G., de Geus, E.J.C., van Beijsterveldt, C.E.M., Bartels, M., Posthuma, D., Boomsma, D.I., Davis, O.S.P., Kovas, Y., Corley, R.P., DeFries, J.C., Hewitt, J.K., Olson, R.K., Rhea, S-A., Wadsworth, S.J., lacono, W.G., McGue, M., Thompson, L.A., Hart, S.A., Petrill, S.A., Lubinski, D., \& Plomin, R. (2010). The heritability of general cognitive ability increases linearly from childhood to young adulthood. Molecular Psychiatry, 15, 1112-1120. http://dx.doi.org/10.1038/mp.2009.55

Hunt, E. (2010). Human Intelligence. New York: Cambridge University Press. http://dx.doi.org/10.1017/CB09780511781308

Johnson, W. (2010). Understanding the genetics of intelligence. Can height help? Can corn oil? Current Directions in Psychological Science, 19, 177-182. http://dx.doi.org/10.1177/0963721410370136

Lawlor, D.A., Batty, G.D., Morton, S.M.B., Deary, I.J., Macintyre, S., Ronalds, G., \& Leon, D A. (2005). Early life predictors of childhood intelligence: Evidence from the Aberdeen Children of the 1950s study. Journal of Epidemiology and Community Health, 59, 656-663. http://dx.doi.org/10.1136/jech.2004.030205 
Lloyd, J. (1992). Educational gains and losses in the Second World War: A Scottish perspective. History of Education: Journal of the History of Education Society, 21, 323-335. http://dx.doi.org/10.1080/0046760920210306

Lloyd, J.M. (1979). The Scottish school system and the Second World War: A study of central policy and administration. PhD thesis: University of Stirling.

MacPherson, J.S. (1958). Eleven-year-olds grow up. London: University of London Press Ltd.

Marwick, A. (1970). Britain in the century of total war: War, peace and social change 1900-1967. Harmondsworth: Penguin.

Maxwell, J. (1961). The level and trend of national intelligence. London: University of London Press.

Odenstad, A., Hjern, A., Lindblad, F., Rasmussen, F., Vinnerljung, B., \& Dalen, M. (2008). Does age at adoption and geographic origin matter? A national cohort study of cognitive test performance in adult inter-country adoptees. Psychological Medicine, 38, 1803-1814. http://dx.doi.org/10.1017/S0033291708002766

Pesonen, A., Eriksson, J.G., Heinonen, K., Kajantie, E., Tuovinen, S., Alastalo, H., Henriksson, M., Leskinen, J., Osmond, C., Barker, D.J.P., \& Räikkönen, K. (2013). Cognitive ability and decline after early life stress exposure. Neurobiology of Aging, 34, 1674-1679. http://dx.doi.org/10.1016/j.neurobiolaging.2012.12.012

Pesonen, A., Räikkönen, K., Kajantie, E., Heinonen, K., Henriksson, M., Leskinen, J., Osmond, C., Forsén, T., Barker, D.J.P., \& Eriksson, J.G. (2011). Intellectual ability in young men separated temporarily from their parents in childhood. Intelligence, 39, 335-341. http://dx.doi.org/10.1016/j.intell.2011.06.003

Roseboom, T.J., Painter, R.C., van Abeelen, A.F.M., Veenendaal, M.V.E., \& de Rooij, S.R. (2011). Hungry in the womb: What are the consequences? Lessons from the Dutch famine. Maturitas 70, 141-145. http://dx.doi.org/10.1016/i.maturitas.2011.06.017

Rutter, M. (1985). Family and school influences on cognitive development. Journal of Child Psychiatry and Psychology, 26, 683-704. http://dx.doi.org/10.1111/j.1469-7610.1985.tb00584.x

Saigh, P.S., Yasik, A.E., Oberfield, R.A., Halamandaris, P.V., \& Bremner, J.D. (2006). The intellectual performance of traumatized children and adolescents with or without posttraumatic stress disorder. Journal of Abnormal Psychology, 115, 332-340. http://dx.doi.org/10.1037/0021-843X.115.2.332

Scottish Council for Research in Education. (1953). Social implications of the 1947 Scottish Mental Survey. London: University of London Press Ltd.

Scottish Council for Research in Education. (1949). The trend of Scottish intelligence: A comparison of the 1947 and 1932 surveys of the intelligence of eleven-year-old pupils. London: University of London Press.

Stein, Z., Susser, M., Saenger, G., \& Morolla, F. (1975). Famine and Human Development: The Dutch Hunger Winter of 1944-45. New York, NY: Oxford University Press.

Stermac, L., Clarke, A.K., \& Brown, L. (2013). Pathways to Resilience: The Role of Education in War-Zone Immigrant and Refugee Student Success. In C. Fernando \& M. Ferrari (Eds.), Handbook of Resilience in Children of War (pp. 211-220). Springer New York. http://dx.doi.org/10.1007/978-1-4614-6375-7 15

Stewart, J. \& Welshman, J. (2006). The evacuation of children in wartime Scotland: Culture, behaviour, and poverty. Journal of Scottish Historical Studies, 26, 100-120. http://dx.doi.org/10.3366/ishs.2006.26.1-2.100

Terman, L.M. \& Merrill, M.A. (1937). Measuring Intelligence: A Guide to the Administration of the New Revised Stanford-Binet Tests of Intelligence. Boston: Houghton Mifflin.

Titmuss, R.M. (1950). Problems of Social Policy. London: His Majesty's Stationery Office.

Walker, S.P., Wachs, T.D., Grantham-McGregor, S., Black, M.M., Nelson, C.A., Huffman, S.L., BakerHenningham, H., Chang, S.M., Hamadani, J.D., Lozoff, B., Meeks Gardner, J.M., Powell, C.A., Rahman, A., \& Richter, L. (2011). Inequality in early childhood: Risk and protective factors for early child development. The Lancet, 378, 1325-1338. http://dx.doi.org/10.1016/S0140-6736(11)60555-2

Yasik, A.E., Saigh, P.A., Oberfield, R.A., \& Halamandaris, P.V. (2007). Posttraumatic stress disorder: Memory and learning performance in children and adolescents. Biological Psychiatry, 61, 382-388. http://dx.doi.org/10.1016/j.biopsych.2006.06.005 
